\title{
CULTURE AND HERITAGE IN DEVELOPMENT
}

\author{
HA LONG ECOMUSEUM, A CASE STUDY FROM VIETNAM
}

\author{
AMARESWAR GALLA
}

\begin{abstract}
The challenge for Vietnam at the turn of the millennium is the 'renovation of national institutions to be compatible with world institutions and participate energetically in the formulation of global institutions'. '. (Vo Dai Luoc)
\end{abstract}

\section{INTRODUCTION}

A sia is currently witnessing the gradual transformation of heritage institutions such as museums, historic places and World Heritage Areas into postcolonial sites of cultural preservation and representation. They are increasingly becoming visitor-centred, exploring their relevance to neighbouring community stakeholders and confronting issues of sense of place and identity in an increasingly globalising environment. ${ }^{2}$ The challenge is to develop a post-colonial heritage discourse that is Asian in philosophy and locally grounded in context. This is largely dependent on the way we address heritage and community building and provide a focus for facilitating productive relationships for collaboration, cultural exchange and enrichment of the 'culture in development' paradigm. ${ }^{3}$

The overriding question facing heritage institutions today in several parts of Asia is that of their relevance and survival. Several of them mirror the reductive, sectarian and typological categories, used by colonial countries, to map, appropriate and control the biocultural landscape of colonised communities. There is a continuation of this paradigm even after decolonisation due to priority focus on social and economic agendas in nation building and community development. The heritage sector has often been left to fend for itself with minimal budgets in a policy vacuum. There have been only rare efforts to reflect or criticise the hegemonic textualisation of the variety, complexity and plurality of the local cultural and heritage contexts through institutions such as museums. ${ }^{4}$

In order to retain their relevance, heritage institutions have to play a role in combating the growing monoculture of life and mind with globalisation, by documenting, preserving and presenting the poly-cultural technologies of resource management, and life enhancing elements of knowledge and skill, transmitted by communities transgenerationally. They have to treat the community habitats as living museums, and collaborate with community groups, in reversing the process of univocal translation of their multicultural societies especially with the convergence of telecommunications. They can play a role in development, not just by commodification of heritage resources for display and representation, but by its revitalisation and replenishment. They have to defend communities against ecological terrorism, their habitats from bio-cultural piracy and museumisation and face up to the challenges of globalisation while taking advantage of new opportunities for strategic partnerships in exploring the economic dimension of heritage conservation in sustainable development. $^{5}$ 
There is an increasing corpus of projects dealing with heritage in development in Asia which are informed by stakeholder group participation through collaborative partnerships to preserve, present and disseminate the specific knowledge systems, cumulative and received heritage of communities through centuries, by responding to different environmental and developmental challenges. These include coexist-curated and coexist-directed field initiatives to channel local governance strategies into sustainable developmental approaches that enable and empower stakeholder community groups in their endeavours for cultural and environmental selfdetermination. These collaborative projects cover various fields including traditional medicine, water harvesting, architecture, conservation of forests and sacred groves, inter-regional transfer of knowledge and technologies, inter dialect translation, locating culture in poverty alleviation and promotion of cross-cultural understanding.

The tensions posed by the centripetal and centrifugal forces of globalisation and localisation/indigenisation provide a contemporary background for heritage institutions in a world increasing governed by free trade market imperatives. In a range of economic and cultural forums, Asian countries have identified economic, telecommunications and cultural impacts of globalisation as of increasing concern for systematic action. The corporate and global process of market integration has affected not only primary industries of agriculture, forestry and mining, or secondary industries of chemicals, drugs and foods, but also tertiary industries of welfare, education, culture, research and advisory services, reducing all social and ecological categories to economic and industrial categories.

The challenge is to come up with principles and processes that govern the transformation of heritage institutions in the twenty-first century resulting in indigenous institutions that excel in the preservation, presentation, continuation and management of movable and immovable, tangible and intangible heritage resources of rich and diverse cultural and environmental systems. They can then play a catalytic role in relating heritage and sustainable development so that culture is seen as constitutive of and not instrumental in development. It will also assist in reorienting heritage tourism to conservation and appropriate economic empowerment of stakeholder community groups rather than the objectification and exploitation of community heritage. As one of the leading thinkers of heritage interpretation in post-independent India, Bendapudi Subba Rao, demonstrated in his work, the endeavour is about understanding and interpreting the personalities of places.

It is within this overall context that a demonstration project auspiced by UNESCO and facilitated by Vietnam will be discussed in this article. The location of the project entitled Ha Long Ecomuseum is centred on the World Heritage Area of Ha Long Bay. The framework used in the project provides a basis for community development that takes advantage of available economic opportunities, and ensures that the benefits flow on to neighbouring community groups. It explores an approach to build economic capacity in modest achievable steps, so as to minimise the risk of economic failure within a situation where heritage conservation and community development are both non-negotiable. And lastly, it aims to consolidate gains, so that each achievement opens up further opportunities and builds further capacity.

\section{HA LONG BAY}

Ha Long Bay is part of the province of Quang Ninh and is located in the northeast corner of Vietnam. It is an area of superlative natural beauty. It is also a treasure house of unusual and often unique geomorphic features, ecosystems and bio-diversity. ${ }^{6}$ There are many sites of historical significance and archaeological remains in and around the Bay and it is strongly represented in the myths and legends of the Vietnamese people.? 
Ha Long Bay is a unique cluster of landscapes and waterscapes created when the rivers and valleys were overtaken by rising sea levels at the end of the Pleistocene or last ice age and during the current Holocene or warm period. There is significant material evidence of human cultures during these transitional periods of climatic history.

The Vietnamese Government made Ha Long Bay a National Protection Area in 1962. It was twice inscribed on the World Heritage List by UNESCO, in 1994 for its outstanding landscape and aesthetic characteristics and then again in 2000 for its scientific and geological values. The Management Department of Ha Long Bay was established in 1995. It is a modest organisation with over 150 employees. The primary functions of the Department are to manage and preserve that part of Ha Long Bay within the boundaries of Quang Ninh Province, which has been inscribed on the World Heritage List and to develop and maintain its values. It provides the staff on the caves and islands, the tourist guides and from its offices in the centre of Hong Gai in Ha Long City, controls all development and activities that take place in the World Heritage Area and its immediate surrounds. The Department also undertakes limited research and development using its own team of professional and technical staff, often with support from national research centres and other countries.

The natural features and the enormously complicated interaction between them and the climatic, hydrological and human influences upon them are, as yet, little researched and therefore largely unexplained. However, it is part of the integrated environmental planning network of Vietnam with considerable focus on the area for future research and development. ${ }^{8}$ It is also an unusually large and unique marine natural heritage surrounded by vigorous industrial, commercial and urban development. In addition to the coalmines in the hinterland, which produce over ninety per cent of coal in Vietnam, tourism has emerged as a major industry con- tributing to almost a third of the provincial economy.

The capacity of the management agency, and therefore the tourist potential of the area is reaching the limits of the Bay's carrying capacity. The bulk of tourism is made up of single-visit short stay visitors placing a maximum demand on the resource but making a minimum economic contribution. The present traditional approach to the management of the heritage area attempts to achieve a balance between the needs of the natural resources and those of economic development. The industrial, commercial, urban, historical and cultural components of the Bay area are managed and treated as separate units.

The Bay and its hinterland is a region which is experiencing significant conflicts between conservation and development. In order to address this emerging crisis situation, management department initiated a project to deal with competing priorities for development. A systematic analysis of the developmental concerns led to the identification of particular issues arising from this situation which are:

- environmental degradation from coal mining activities,

- discharge of industrial waste, sewage and stormwater run-off from urban areas,

- pollution and sedimentation from rural stormwater run-off,

- urban infrastructure that is inadequate to cope with development pressures,

- lack of institutional capacity to address development conflicts,

- lack of an appropriate regulatory regime,

- lack of an appropriate spatial plan that can resolve the tension between competing uses.

Pollution sources include the expanding urban population and small scale manufacturing industries as well as upstream coal 

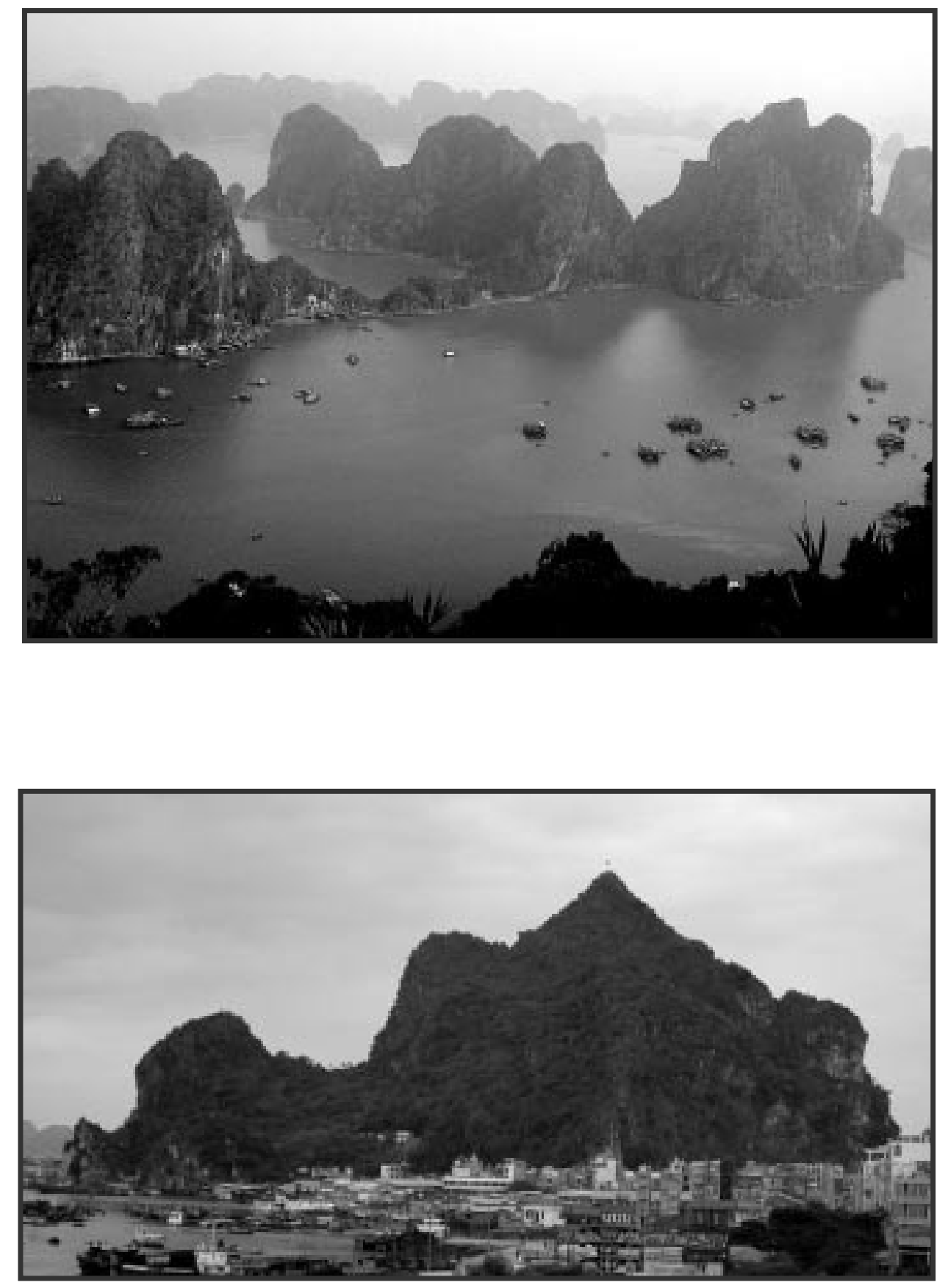

Views of Ha Long Bay.

Photos: Amareswar Galla. 
mining. The pollution problem is compounded by the fact that there is no adequate waste water treatment facility in the urban area of Hon Gai, the central city area of the Bay. What infrastructure does exist is often old, and was designed for a much smaller population. This includes an estimated ten kilometres of old and leaking sewers. Pollution of land and water is likely to have long-term adverse impacts on the health of the local community, as well as discouraging tourist visitation. The environmental quality of $\mathrm{Ha}$ Long Bay will continue to deteriorate if there is no substantial investment in upgrading its infrastructure and management systems. ${ }^{9}$

In order to address these concerns the Management Department of Ha Long Bay and the Quang Ninh People's Committee (the provincial authority) have jointly developed a 'Master Plan for the Development of Ha Long Bay to the Year 2020'. This was ratified by the prime minister in January 2001. It will provide a coordinated planning framework to control development that could affect the Bay but lies beyond the protection of the World Heritage Area and the area of national protection. Nevertheless, many current, and possible future activities conflict with efforts to manage the sustainable development of the marine resources and World Heritage values of Ha Long Bay. Clearly identifiable examples of direct conflicts are the impacts of increasing numbers of tourists and the corresponding demand for wider access to caves and grottoes, expansion of commercial shipping and tourist vessels, fishing by using explosives and other illegal methods as well as coal mining.

In addressing the above mentioned conflicts between conservation and development the official and community stakeholder groups adopted in July 2000 the mediation processes embedded in the philosophical frameworks of ecomuseology. The directive was that both conservation and development were non-negotiable and that the Ha Long Bay Management Department had to come up with the best possible approach to estab- lish a way forward. Hence the launching of the Ha Long Ecomuseum project.

RESOLVING CONFLICTS BETWEEN CONSERVATION AND DEVELOPMENT

The development of the ecomuseological approach to resolve the conflicts between conservation and development and the use of the Ecomuseum as a tool for conservation in sustainable development were the result of a year-long process of stakeholder meetings, workshops and mapping of community heritage values. Some of the findings of the community driven consultation process are as follows:

1. Income generation from the growth of tourism has become critical for mass poverty alleviation and job creation. But tourism is expanding rapidly and only exploiting a minimal product range. The carrying capacity of the Bay is at its limits based upon current levels of development and can only be raised by opening up more islands and caves or by diversification of the range of interpretive products for visitors beyond the confines of the World Heritage Area boundary.

2. The organisational and management capacity of the Management Department of Ha Long Bay is sound within its present limited role. Significant expansion of capacity is essential if more sophisticated planning, development, implementation and evaluation techniques are to be employed. Research indicates that capacity has to be built by intensive expertise and skills transfer activities starting from a primary conceptual base and taking deeply rooted cultural patterns into account. Experience shows that such investment in building basic management and planning concepts pays rich dividends in terms of subsequent 
institutional change and rapid organisational development.

3. Extensive current and planned urban and industrial development outside the World Heritage Area is creating real and potential threats to the natural environment and, in particular, the tangible and intangible culture and heritage of Ha Long Bay. Whilst some of the pressures on the natural environment are being effectively addressed through infrastructure improvements and better equipment, measures to mitigate damage and pollution arising from the irresponsible activities of residents, visitors and local industries are minimally effective.

4. Although the local area is rapidly becoming more prosperous, there are increasing problems of occupational displacement, marginalisation and social alienation of vulnerable and minority ethnic groups and increasing relative poverty. Preliminary discussions and negotiations with individuals and groups of those affected demonstrate that the establishment of strategic partnerships, an integral part of the Ecomuseum development, will have a powerful mitigating effect on these problems.

5. Although definite projections have yet to be quantified, it is clear that the Ecomuseum will create a wide range of direct and indirect employment opportunities biased in favour of marginalised and poor people.

6. The limited range of activities undertaken to establish the feasibility of the Ecomuseum have already had a considerable effect upon raising public awareness of the importance of heritage conservation. It is equally apparent from the consultation exercise that there is a clear recognition that conservation is essential to ensure future economic prosperity. There is also surprisingly strong support for positive actions to achieve it through partnerships with the Ecomuseum.

7. The capacity of the Management Department of Ha Long Bay is limited by its present organisational structure and culture. The holistic nature of the Ecomuseum, which approaches development through interpretive themes and demonstration projects is a catalyst in breaking down the conceptual limits imposed by the present structure.

8. Liaison between agencies and departments at an operational level is very limited except in situations where cooperation is enshrined in a formal decree, as in the example of the inspection activities undertaken by the Department in collaboration with other agencies. However, during the Ecomuseum developmental process it is being discovered that informal relationships and partnerships are not only possible, but welcomed. Working together in this way is regarded as an innovative activity and offers manifold opportunities to explore inter-sectoral synergies.

9. Local authority administrative infrastructure needs to be improved. Considerable expertise is available in local government departments and offices but administrative procedures and processes need to be streamlined to benefit from rapidly growing markets and economic development. Nevertheless, there is a willingness among all the stakeholders to cooperate at a local level and to assist 
with new ventures such as the Ecomuseum. However, it is important to recognise that capacity building will need to extend well beyond the confines of the Management Department of $\mathrm{Ha}$ Long Bay if developments there are not to founder in complex administrative processes.

10. Perhaps the most important element in the development of the Ecomuseum is its potential for energising community support and conservation awareness. At present, most members of the Ha Long community are almost completely oblivious to the global importance of the heritage of the area and the great significance of the culture and history of the $\mathrm{Ha}$ Long Bay to the nation. This lack of awareness leads to indifference to attempts to control damaging environmental activities by means of exhortation and regulation. The Ecomuseum development has shown that, by engaging interest groups in dialogue and partnership, it is possible to bring issues of conservation to the forefront of public consciousness and to have a substantial positive impact on irresponsible patterns of behaviour.

The Ecomuseum developmental study contextualised all elements of its proposals within the population profile of Ha Long Bay and Quang Ninh Province. The demographic profiles clearly demonstrated that there is a significant youth population, both male and female, especially in the rural areas of the province. It is envisaged that the children and young people, both male and female, will be seeking new opportunities in the growth of the provincial economy. They will also be the critical players in dealing with new markets and opportunities as well as being responsible for conservation in sustainable development.
The Ecomuseum places special emphasis on the women, youth and children of Quang Ninh in all pilot or demonstration project development. These groups and their participation and interest cut across all the current and proposed projects.

\section{HA LONG ECOMUSEUM CONCEPT}

The Ha Long Ecomuseum has caught the imagination of the nation through extensive interest among the various conservation agencies and the media. It is a flexible project driven by the simple principle that the conflicts between conservation and development could only be dealt with by bringing people and their environment together into productive partnerships. The following is a summary of the project concept, which was developed through a stakeholder participation framework during 2000-2001. ${ }^{10}$

Theory: The Ecomuseum concept views the entire Bay as a living museum and employs an 'interpretive' approach to its management. ${ }^{11}$ Interpretive management sees the components and processes of the Bay and its hinterland of Quang Ninh Province as continuously interacting with each other in a constantly changing equilibrium. By intensive research and monitoring, managers and stakeholder community groups seek to 'interpret' what is happening to that equilibrium and to make carefully planned interventions to change the balance of the components when necessary. An important feature of this approach is that it views human activity, past and present, as fundamental components of the total environmental resource. The culture, history, traditions and activities of the human population on and around the Bay are as much a part of the heritage as the caves and plants on the islands and are in continuous interaction with it.

Assumptions: all human and natural ecosystems are living, developing organisms that cannot be 'preserved' in a particular isolated state: 
- human and natural ecosystems are interdependent,

- the ultimate goal of conservation is the sustainable development of the resource,

- to sustainably use and develop the resource it is necessary to understand it,

- to understand the resource it is necessary to interpret its nature and processes,

- effective interpretation must be based upon a holistic view of the resource which recognises the interdependence of its elements, systems and processes.

In practice the Ecomuseum means different things for different stakeholder and participant groups as follows.

For the visitor: At the heart of the Ecomuseum is the Hub or a central interpretive centre under construction, the gateway through which all visitors pass en route to the Bay. It will be a large, well-designed building capable of dealing with a large throughput of visitors. Inside, there will be much that is reminiscent of a conventional museum displays, dioramas, models, natural history exhibits, hands-on interactives and so on, but all carefully themed and relating directly to the various 'ecosystems' of the Bay and its hinterland.

The Ecomuseum Hub will provide an exciting 'summary' of the complexity of the area - its history, traditions, industries, commerce and so on, as well as the caves, islands, geomorphology and seascape. From there, the visitor can choose a 'tour' or cultural experience. A cultural tour might take in a fishing village, a temple, and a visit to a craft factory or a convenient local event — not something that has been specially staged. An industrial tour could take the visitor to a restored traditional coal mine, followed by a visit to its working counterpart with an interpretation of the mine workers and their role in resistance against colonialism and during the
American war. The potential for interesting and exciting experiences that will give tourists a real insight into the area is almost limitless. Instead of a single visit to look at and photograph the islands and caves as is the current situation, a visitor could spend a fortnight in Ha Long City and immerse themselves in a different cultural experience every day if they so wished along different thematic cultural routes across the Quang Ninh Province that are being developed as pilot projects.

The Ecomuseum Hub will continue to research and examine these possibilities as well as considering options for expanding the recreational and learning facilities to support the Ecomuseum activities. It would also contain quality restaurant and refreshment facilities, a large outlet for locally-produced products and crafts and a performance space. It will also have a marine educational centre with exhibits and educational programs and outreach activities that focus on environmental education. The Ecomuseum would act as both a capacity-building mechanism and a quality control agency for all products - a certification that could extend into the wider retail community.

For the local people: Apart from justifiable pride in the establishment of the first Ecomuseum in Vietnam, local people will benefit in many ways. The Museum will generate direct and indirect employment opportunities and stimulate interest and a market for traditional local industries and crafts. Substantial additional revenue will accrue from the longer stays of visitors further stimulating the local economy. Those working directly in traditional ways will have the opportunity to become a living resource - in return for upgrading their workshop, boat or World Heritage Area or whatever, and undertaking appropriate training, they will be subsidised in the practice of their skill and become effective custodians of aspects of the Bay's living culture and heritage.

The Hub will also have a significant Discovery Centre for use by local teachers and 

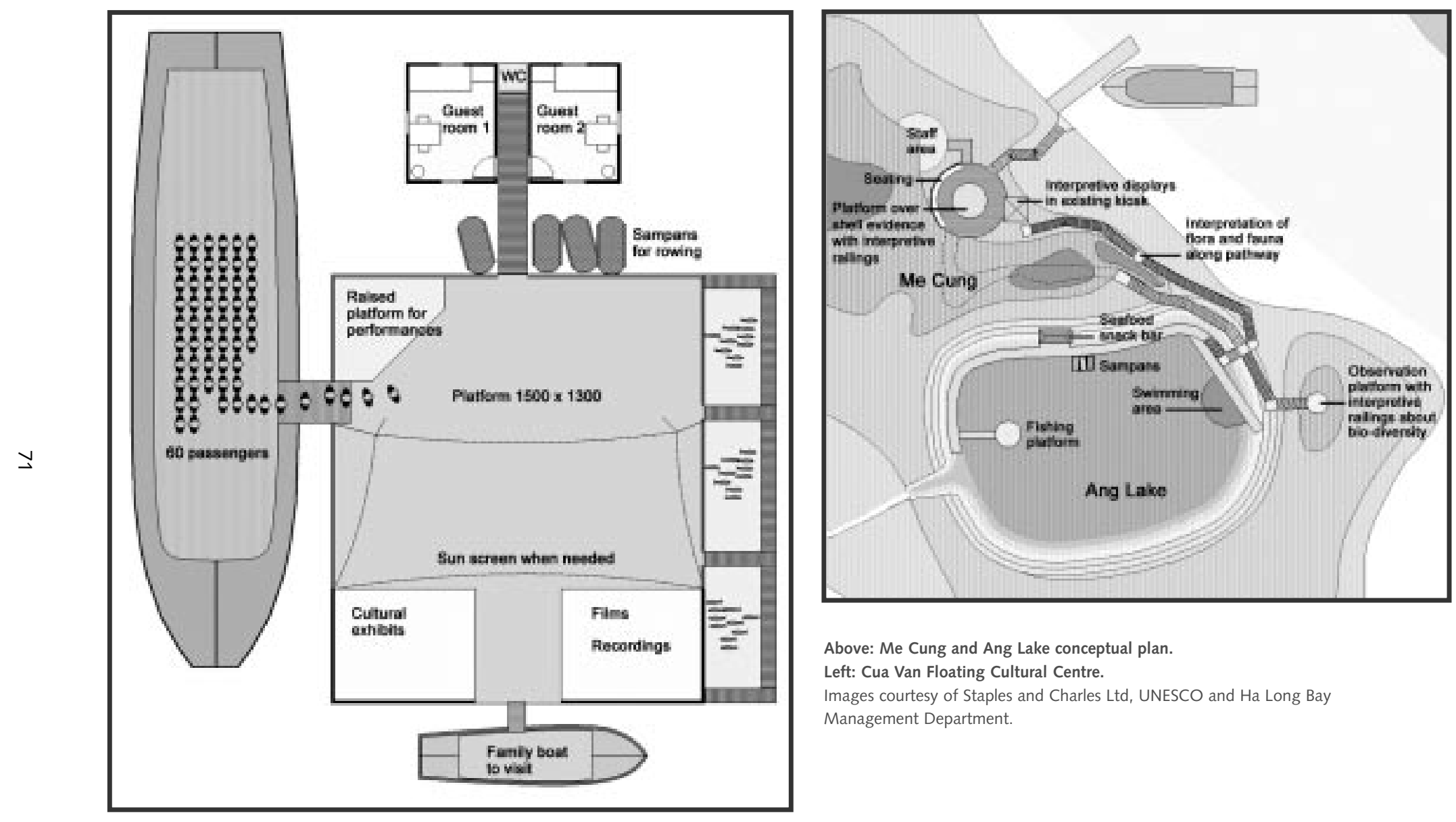

Above: Me Cung and Ang Lake conceptual plan

Left: Cua Van Floating Cultural Centre.

Images courtesy of Staples and Charles Ltd, UNESCO and Ha Long Bay

Management Department. 
school children as a strategic partnership with the Department of Education. One of the exciting elements of the Discovery Centre is the Ecomuseum Boat, similar to a museum bus, which will go to the various schools of the Quang Ninh Province. The majority of them are located on the edge of waterways. Children will be given free educational experiences on the Bay. It will be developed and managed as a strategic partnership with the Quang Ninh Youth Union as a young people in heritage conservation project.

For the managers: The development of the Ecomuseum is of necessity accompanied by an extensive training program to provide the advanced skills needed to manage a complex organisation. The effectiveness of interpretive management depends upon the quality of the data collection, storage and retrieval mechanisms needed to update the information resource and further refine the interpretation of the heritage. This activity and the scientific research that will accompany it will become a much more significant task. Implementing the newly-established Interpretive Management Plan through the Ecomuseum process will involve learning new working practices based on information sharing, team working and more generic roles.

Improved skills will be necessary throughout the organisation. The use of computers and electronic aids to management and data processing will be essential. Tourist guides will become highly trained professionals: fluency in foreign languages and interpersonal skills will become even more significant.

For the local authority: The creation of the Management Department of Ha Long Bay was groundbreaking at the time inasmuch as it created an agency, which crossed the demarcation lines of different Departments of the People's Committee. The establishment of the Ecomuseum will take that successful innovation a stage further by prompting more extensive inter-agency collaboration to promote conservation in sustainable development. There is already a careful consideration of the legal framework that presently governs activities on the Bay and refinements for the establishment of the Ecomuseum framework are in the pipeline.

\section{HOLISTIC CONTEXT FOR HERITAGE IN DEVELOPMENT}

The research and development for the $\mathrm{Ha}$ Long Ecomuseum are conducted with a focus on three issues that are of growing concern for developing community-grounded heritage projects in Vietnam. These are: integrated and holistic approaches to heritage management that are local in context and global in professional orientation, capacity building for all the stakeholder groups who are critical for sustainable development initiatives and quality heritage interpretation that is informed by the demographic and psychographic profile of diverse audiences. In the context of locating the human face in globalisation, a commitment to the framework of integrated heritage management has been adopted by Vietnam through the national cultural heritage law and its regulations in 2001.

It is within this context that the Ha Long Ecomuseum is informed by a holistic approach to natural and cultural environments and to movable and immovable heritage resources, including tangible and intangible elements. This approach adopted from the proceedings of the Nara Convention on Authenticity of the World Heritage Bureau is diagrammatically represented below.

Heritage interpretation through Ha Long Ecomuseum has been situated within this holistic context that brings together people and their environment, focusing on both natural and cultural resources. For example, effective presentation and interpretation can be a significant force for changing attitudes towards Ha Long Bay's environment and its conservation. Interpretation can legitimise or challenge particular ideas and viewpoints. It can inform public awareness of key issues in Vietnamese society, such as the environment, sustainable development and understanding 


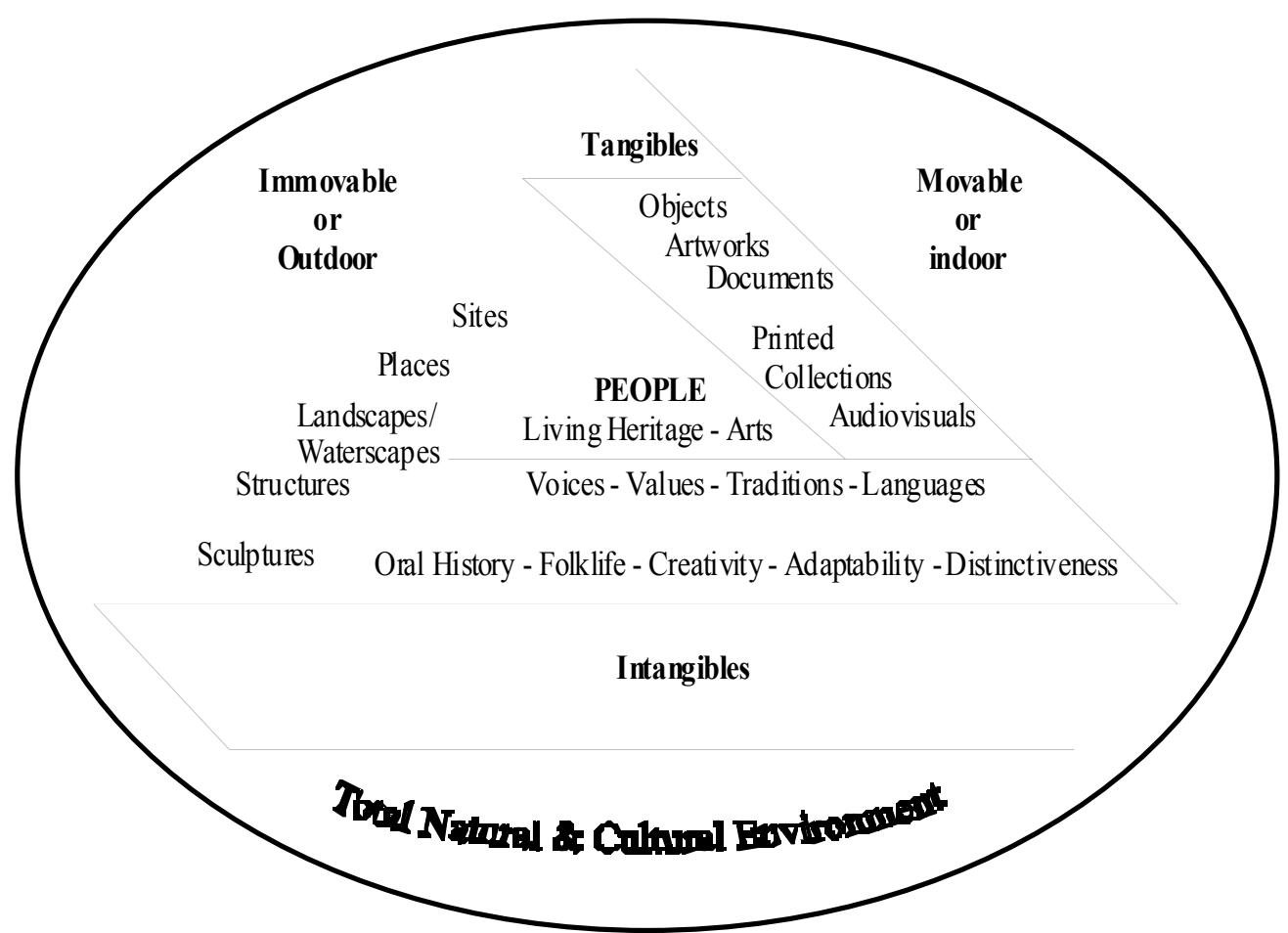

Holistic Representation of Cultural and Heritage Resources ${ }^{16}$ ๑) A.Galla \& P. Yu.

the cultures of communities in the neighbourhood of the World Heritage Area. It can bring multiple publics to the World Heritage Area and the World Heritage Area to the multiple publics. Ha Long Ecomuseum aims to achieve a balance between area-centred and people-centred approaches to environmental and cultural conservation.

Appropriate heritage interpretation is seen as the key to the re-establishment of cultural pride and a sense of place to addressing social well-being and promoting conservation values. It requires an inclusive framework that recognises the cultural aspirations of different sections of the community, including groups that may otherwise be marginalised culturally, socially or economically.

An essential component of cultural recovery and maintenance is the passing on of cultural values to the younger generation. One of the pilot projects of the Ha Long
Ecomuseum makes provision for heritage education for young people within the broader programs for economic development. The possibility for employment is likely to create a powerful incentive for young people to learn about their heritage, and provision of cultural education for youth is likely to encourage broad community support for economic development projects. In some situations, recognition and respect for traditional heritage is critical to maintaining the integrity of local cultural resources.

The capacity of the stakeholder organisations in the development of Ha Long Bay at present is heavily influenced by the organisational infrastructure available at a local level. Ha Long Ecomuseum development will specifically address issues of leadership, organisational capacity, governance, collaboration, core skills, information and resource management through an integrated stake- 
holder participation framework. The typology of capacity building and the social context calls for community building through localised empowerment of communities for sustainable development. The tools will at once provide the skills for working in a holistic environment that reconciles concerns of globalisation with indigenisation and localisation.

They underline central issues in community building, sustainable development and the importance of professionalism, including the need for furthering scholarship. It is critical to offer an opportunity to think about attitudes, to acquire knowledge and to hone skills to all stakeholder groups associated with the development of Ha Long Bay, for this is the foundation of sound decision making and sustainable outcomes. Heritage in development is a process by which communities can recognise and assert the value of their cultural wealth, and thus protect and enhance their cultural resources in all aspects of planning for the development. It is essentially community based, founded in 'bottom-up' approaches to community empowerment and capacity building. Ha Long Ecomuseum development is applying a range of methodological tools, including community planning, cultural mapping and cultural planning. Communitygrounded development is vital to Ha Long Bay through the Ecomuseum development because it has the potential to:

- strengthen and protect the cultural and heritage resource base for sustainable expression and practice through interpretation,

- engage the whole community in valuing and participating in heritage conservation and appreciation,

- provide relevant community infrastructure for the support of conservation activity,

- develop the economic framework for the promotion of the conservation values through resolving conflicts and maximising on the opportunities for job creation and poverty alleviation.

In pursuing economic development through interpretation, it is vital that the value of local resources is protected. This applies not only to the physical environment, but also to cultural and heritage resources. The frameworks of environmental impact assessments is being reworked to include social and cultural impact assessments as well. The Ecomuseum Hub has provision to establish and maintain stations in the province for effective monitoring of the impacts of all developments in Ha Long Bay.

A range of pilot projects that is being implemented by the Ha Long Ecomuseum provides a basis for community economic empowerment that takes advantage of available opportunities, and ensures that the benefits flow on to neighbouring communities of the Bay. These pilots will be used as a foundation for economic planning and action within each node of heritage resources in Quang Ninh Province enabling participation by all groups within neighbouring communities, Management Department of Ha long Bay and other external stakeholder agencies. They is a strong consciousness now to build economic capacity in modest achievable steps, so as to minimise the risk of economic failure within already disadvantaged communities.

\section{CONCLUSION}

Ha Long Bay is sometimes referred to as a microcosm of Vietnam. This is certainly so inasmuch as it clearly shows the conflict between conserving a rich, but fragile, heritage whilst simultaneously promoting the industrial, economic and tourism development that is essential to alleviate the severe poverty and impoverishment of large sections of the community. Traditionally, this has been treated as an 'either/or' issue and therefore frequently results in an impasse.

The greatest challenge has been to bring together the Ha Long Bay World Heritage 
Area management and all the stakeholder groups into a participation framework that is facilitated by the Ha Long Ecomuseum development. The partnership promotes the identification of the aims, interests and values that inform interpretations of community, local history and holistic environmental values, including the intangible heritage values.

The Ecomuseum offers a way forward. Through the establishment of a far broader stakeholder base, involving communities, groups and organisations, in the management of the heritage resources, it seeks to establish a mutuality of interest and a sense of common ownership. Through interpretation it raises awareness and understanding, not only of the significance of the natural and cultural heritage, but also of the contribution of industrial and commercial development to the betterment of a poor country striving to recover from almost a century of war and famine. Better understanding of the critical importance of both conservation and development softens the polarisation of the debate and enables the two issues to be viewed holistically.

The development of the Ha Long Ecomuseum will examine some of the implications and dilemmas of interpreting environmental resources and cultural heritage for visitors while protecting the significance and integrity of the resources.

The role of the Ecomuseum can be summarised as:

- supporting communities in securing their basic living needs (this may require advocacy with other agencies),

- facilitating the community planning process within communities, including the identification of local resources,

- supporting the protection of local resources, including cultural maintenance,

- developing skills and providing other business support infrastructure, including funding and communications infrastructure,

- launching businesses through contracting and outsourcing, and provision of space for community markets,

- growing enterprises and employment through developing a prospectus for any business opportunity with good prospects for viability,

- supporting communities in making wise investments, and increasing their economic resources,

- facilitating demonstration projects such as the pilot projects that will be catalytic.

The Ha Long Bay dilemma is far from unique to Vietnam. However, whilst the application of 'new museology' or ecomuseology has been recognised as a valuable tool to mitigate development conflicts in several countries, it has yet to become established in an Asian context. Projects such as the Ha Long Ecomuseum could become models for promoting heritage economics without compromising conservation values; models in which the economic dimension of conservation will be revealed in a World Heritage Area through community museological discourse. The Ha Long Ecomuseum development is being viewed as an exemplar for similar developments elsewhere and will be an important factor in the creation of a national policy for sustainable heritage tourism in Vietnam. ${ }^{13}$

\section{Endnotes}

1 Vo Dai Luoc, "Globalisation and Vietnam's World Integration Issue", in Vietnam Economic Review, special issue on Globalisation and Integration, National Centre for Social Sciences and Humanities, No. 4, April 2000, pp. 10-11 focus on the importance of locating culture in development.

2 A. Galla, "Museums, Globalisation and Sustainable Partnerships", in Karl Magnusson (ed.), Reforming Museums for the 21st Century, (Stockholm:

International Council on Museums, 2000). 
3 Manila Declaration on Museums and Community Building, Proceedings of the Asia Pacific Regional Assembly of the International Council of Museums, Manila, November 1997.

4 Theme Statement, "Museums, Culture and Development, South Asia" Seminar, ICOM Asia and Pacific Organisation, Indira Gandhi Rashtriya Manava Sanghralaya, Bhopal, January 2000.

5 K.K.Chakravarty, Opening address, "Museums, Culture and Development, South Asia".

6 This approach provides the main direction for the Asia Pacific Executive Board of the International Council of Museums for the period from 1998-2004. See also, Our Creative Diversity, Final report of the World Commission for Culture and Development, (Paris: UNESCO, 1996); and the Stockholm Action Plan adopted by the Inter Governmental Conference on Cultural Policies, 1998.

7 Bendapudi Subba Rao, The Personality of India, Pune, 1972. See also Romila Thapar, Past and Prejudice, Father Heras Memorial Lectures, Bombay, 1976.

8 I am grateful to the following who were critical for the development of the Ecomuseum Project where I worked as the capacity building facilitator and principal technical adviser. The project Management Team consists of the following: $\mathrm{Mr}$ Nguyen Van Tuan, Project Director; Dr. Amareswar Galla, Principal Technical Adviser; Mr Len Tooke, Project Manager; Mr Ha Huu Nga, Archaeologist; $\mathrm{Mr} \mathrm{Vu}$ Nam Phong, Environment Expert; Ms. Ngo Thi Mai Phuong, Member; Ms. Nguyen Thi Kim Hoa, Member; Mr Nguyen Quang Hao, Member; Ms. Nguyen Thi Van, Member; Mr Nguyen Quang Vinh, Member; Ms Pham Quynh Lam, Member; Ms Nguyen Thu Huyen, Member; Ms Nguyen Thi Tam, Member; Ms Le Thi Huyen, Member. The project is facilitated by Ms Rosamaria Durand, Representative of UNESCO in Vietnam; Mrs. Nguyen Thi Hoi, Secretary General, National Commission for UNESCO of Vietnam and Ha Van Hien, Chairman of Quang Ninh Provincial People's Committee.

9 Pham Hoang Hai, Ha Long Bay Tourism, Ha Long Bay Management Department, Ha Long Bay, 2000; The Legal Documents Related to Conservation and Management of Ha Long Bay, Ha Long Bay Management Department, The Gioi, Ha Noi, 1998; Nguyen Van Tuan, Ha Long: Evaluations Acclamations, Ha Long Bay Management Department, Ha Long city, 2000; Options for Comprehensive Development in Quang Ninh and Hai Phong Coastal Region, Seminar Proceedings,
World Bank, World Bank Place, Hanoi, 1999.

10 Ha Huu Nga, The History of Ha Long, (Ha Long City: Ha Long Bay Management Department, 1999).

11 Ha Huu Nga and Nguyen Van Hao, Ancient Ha Long, (Ha Long City: Ha Long Bay Management Department, 1999).

12 David C. Wege et al., Expanding the Protected Areas Network in Vietnam for the 21st Century, An Analysis of the current system with recommendations for equitable expansion, Forestry Inventory and Planning Institute and Birdlife International Vietnam, Conservation Report No. 6, (Hanoi: Birdlife International, 2000).

13 Pham Quang Tho and Nguyen Van Tuan, "Local Communities and the Management of the World Natural Heritage of Ha Long Bay", in Hans D. Thulstrup (ed.). World Natural Heritage and the Local Community, Case Studies from Asia-Pacific, Australia and New Zealand, (Hanoi: UNESCO, World Heritage Centre, 1999), pp. 130-135.

14 Amareswar Galla, Ha Long Ecomuseum Feasibility Study, (Hanoi: UNESCO, 2001).

15 Riviere, Georges - Henri, "Le musée de plein air des Landes de Gascogn: Expérience française d'un musée de l'environment", in Ethnologie Françoise, Volume 1, 1972, pp.87-95; Varine, Hugues de. Musées pluridisciplinaires et interdisciplinaire (Paris: Ecomusées, 1983); Rivard, René. Que le musée s'ouvre... ou vers une nouvelle muséologie: les écomusées et les musées 'ouverts', Quebec, 1984; Musée et Centre Regional d'interpretation de la Haute-Beauce, Collectif de treize village, St. Evariste, 1982; Ghose, Saroj. "Science Museums Beyond Their Four Walls", in Museum, Vol. 38, 1986, No.2, pp. 100-106; Bedekar, V.H. Museums and Community Building, (New Delhi: National Museum Institute, 1999).

16 Amareswar Galla, "Authenticity: Rethinking Heritage Dversity in a Pluralistic Framework", (Paris: Nara Convention on Authenticity in Relation to the World Heritage Convention World Heritage Bureau, UNESCO, 1995), pp. 315-322; A. Galla, Heritage Curricula and Cultural Diversity, National Guidelines for Museum Training, (Canberra: Office of Multicultural Affairs, Prime Minister and Cabinet, 1993).

17 A substantive monograph based on three years of fieldwork and first-hand project development is being finalised by the author on a Visiting Fellowship in the Humanities Research Centre at The Australian National University during 2002. 